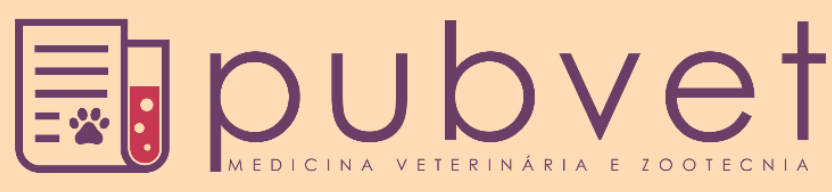

https://doi.org/10.31533/pubvet.v14n7a616.1-7

\title{
Desbridamento com broca de diamante em gato com úlcera refratária: relato de caso
}

\author{
Tarcísio Guerra Guimarães ${ }^{1,2,3,4^{*}} \bullet$ (D), Karla Menezes Cardoso $\mathbf{1}^{1,3,6} \bullet(\mathbb{D}$, Fabricio Villela \\ Mamede $^{50}$, Susana Faim ${ }^{6}$, Ana Catarina Figueira ${ }^{6,7}{ }^{\mathbb{D}}$, Hugo Vilhena ${ }^{6,7,8}$ \\ ${ }^{I}$ Instituto de Investigação e Formação Avançada (IFA), Universidade de Évora, Portugal. \\ ${ }^{2}$ Instituto de Ciências Agrárias e Ambientais Mediterrânicas (ICAAM), Universidade de Évora, Portugal. \\ ${ }_{3}^{3}$ Instituto de Investigação Clínica e Biomédica (iCBR), área de Meio Ambiente, Genética e Oncobiologia (CIMAGO), Faculdade de Medicina, \\ Universidade de Coimbra, Portugal. \\ ${ }^{4}$ Fundação para a Ciência e a Tecnologia (FCT), Portugal. \\ ${ }^{5}$ Centro de Oftalmologia Veterinária, Oftalmocenter Vet, Ribeirão Preto, São Paulo, Brasil. \\ ${ }^{6}$ Hospital Veterinário Universitário de Coimbra (HVUC) Coimbra, Portugal. \\ ${ }^{7}$ Centro de Investigação Vasco da Gama, Departamento de Ciências Veterinárias, Escola Universitária Vasco da Gama, Coimbra, Portugal. \\ ${ }^{8}$ Centro de Ciência Animal e Veterinária (CECAV), Universidade de Trás-os-Montes e Alto Douro (UTAD), Vila Real, Portugal. \\ *Autor para correspondência, E-mail: tarcisiounifran@yahoo.com.br; tarcisioguerra77@gmail.com
}

Resumo. A úlcera refratária é caracterizada por uma lesão espontânea superficial da córnea, geralmente recidivante, e que não cicatriza dentro de um período habitual de tratamento. É ocasionada pela não aderência do epitélio ao estroma corneano. O diagnóstico é realizado pelo curso clínico e característica da lesão, observadas através de exame e testes oftalmológicos. Além do tratamento terapêutico adequado, deve ser removido o epitélio não aderente, a fim de facilitar o crescimento de novas células epiteliais, com complexos de adesão mais fortes. A broca de diamante (DB), destaca-se de forma promissora no tratamento para as úlceras refratárias, através da ceratectomia superficial. O procedimento com a DB é descrito em variadas espécies, contudo é raramente descrita em gatos. Dessa forma objetivou-se relatar o emprego da DB no tratamento de úlcera superficial não cicatrizante em um gato. O DB mostrou ser um dispositivo eficaz, de fácil aplicação, bem tolerado e seguro, na resolução de uma úlcera de córnea refratária num gato da raça Persa.

Palavras chave: Diamond burr, felino, sequestro corneal, tratamento, úlcera

\section{Debridement with diamond burr in cat with refractory ulcer: case report}

Abstract. The refractory ulcer is characterized by a spontaneous superficial lesion of the cornea that is usually recurrent and does not heal within a suitable period of treatment. It is caused by the non-adherence of the corneal epithelium to the stroma. The diagnosis is established by the clinical course and characteristics of the lesion, observed through e ophthalmological examination. The appropriate treatment includes the removal of the nonadherent epithelium, to facilitate the growth of new epithelial cells, with stronger adhesion complexes. The diamond burr (DB) stands out promisingly in the treatment for refractory ulcers, through superficial keratectomy. The procedure with DB is described in several species, however, it is rarely described in cats. Thus, the objective was to report the use of DB in the treatment of a superficial non-healing ulcer in a cat. The DB proved to be an effective device, easy to apply, well-tolerated and safe, in the resolution of a refractory corneal ulcers in a Persian cat.

Keywords: corneal sequestration, diamond burr, feline, treatment, ulcer 


\section{Desbridamiento con fresa diamantada en gato con úlcera refractaria: reporte de un caso}

Resumen. La úlcera refractaria se caracteriza por una lesión superficial espontánea de la
córnea, que generalmente es recurrente, y que no cicatriza dentro de un período adecuado de
tratamiento. Es causada por la no adhesión del epitelio al estroma corneal. El diagnóstico se
realiza por el curso clínico y las características de la lesión, observada mediante examen y
pruebas oftalmológicas. Además del tratamiento terapéutico apropiado, el epitelio no adherente
debe eliminarse para facilitar el crecimiento de nuevas células epiteliales, con complejos de
adhesión más fuertes. La fresa diamantada (DB) se destaca de manera prometedora en el
tratamiento de las úlceras refractarias, a través de la queratectomía superficial. El procedimiento
con BD se describe en varias especies, sin embargo, rara vez se describe en gatos. Por lo tanto,
el objetivo fue describir el uso de BD en el tratamiento de úlceras superficiales refractarias en
gatos. El DB demostró ser un dispositivo eficaz, fácil de aplicar, bien tolerado y seguro, en la
resolución de una úlcera corneal refractaria en un gato Persa.

Palabras clave: Diamond burr, felino, secuestro corneal, tratamiento, úlcera

\section{Introdução}

O defeito epitelial corneano espontâneo crônico ou úlcera refratária, são nomes empregados para designar úlceras superficiais não cicatrizantes de difícil resolução, cuja a lesão é resultante da separação do epitélio do estroma anterior da córnea, sem causa subjacente discernível (Grahn \& Peiffer, 2007; Maggs et al., 2017). Úlceras refratárias podem acometer cães (Hung et al., 2020), gatos (Grahn \& Peiffer, 2007; Maggs et al., 2017), cavalos (Pigatto et al., 2017) e outras espécies (Mamikonyan et al., 2018; Waugh et al., 2017; Wolfer \& Rich, 1992). Entre as principais manifestações clínicas, apresentase variados graus de blefarospasmo, fotofobia e epífora (Maggs et al., 2017).

O diagnóstico da úlcera refratária, advém dos sinais clínicos, do teste com fluoresceína sódica, observando a retenção do corante na superfície corneana com penetração do espaço subepitelial e da não adesão epitelial que pode ser verificada tocando um swab estéril e assim, evidenciando o epitélio solto (Crivellentin \& Borin-Crivelletin, 2015). Possuem ainda curso prolongado e tendem a recidivar (Hvenegaard et al., 2011).

Além do tratamento terapêutico adequado, diversos procedimentos são relatados e indicados para a resolução dessa desordem (McGrath \& Lee, 2014). Dentre os procedimentos, destacamos o emprego da DB, para o desbridamento pela ceratectomia superficial da córnea acometida (Malta \& Soong, 2008). Esse procedimento é apresentado de forma frequente e atual na resolução de úlceras refratárias em cães (Hung et al., 2020). Revelando ser um procedimento seguro e eficaz em sua aplicação (Hung et al., 2020; Silva et al., 2011). O emprego da DB na resolução de úlceras refratárias é raramente descrito em gatos. Dessa forma, objetiva-se relatar o emprego da DB no tratamento de úlcera superficial não cicatrizante em um gato da raça Persa.

\section{Relato de caso}

Foi atendido no serviço de oftalmologia veterinária do Hospital Veterinário Universitário de Coimbra (HVUC), um gato da raça Persa, fêmea castrada, com oito anos de idade, vacinação atualizada, domiciliado, sem presença de concomitantes e com história pregressa de tratamento clínico para sequestro de córnea no olho direito. $\mathrm{O}$ animal foi consultado devido a queixa de desconforto ocular no olho esquerdo, sem o histórico de trauma.

Ao exame oftalmológico observou-se blefarospasmo, fotofobia e epífora. Nos exames de resposta a ameaça, reflexo de ofuscamento, pupilar a luz direto e consensual, responderam positivamente. Não foi observado alterações ciliares e palpebrais. Com o biomicroscópio em lâmpada de fenda (SL 15, Kowa ${ }^{\circledR}$ ) observou olho esquerdo com úlcera superficial com discreto edema de córnea com o contorno irregular e bordas elevadas, localizada em região axial, sem presença de sinais inflamatórios e ausência de vascularização da córnea. O teste de fluoresceína sódica evidenciou a perda da integridade da córnea, corando e penetrando abaixo do epitélio solto (Figura 1A), não foi observado evidências de lesões 
geográficas ao teste de rosa bengala. O olho contralateral apresentava-se fisiológico e à biomicroscopia revelou a presença de cicatrizes na córnea (nébula). Instilou-se na superfície ocular do olho esquerdo uma gota de colírio anestésico contendo cloridrato de oxibuprocaína (Anestocil ${ }^{\circledR}$ ) e com auxílio de um swab estéril com ponta de algodão, realizou-se discreto toque na periferia da lesão, evidenciando despendimento, elevação da borda epitelial e aumento da extensão da lesão. Foi ainda indicado a pesquisa para herpesvírus felino (FHV-1), a qual não foi autorizado pelo proprietário. Devido aos sinais clínicos e característica da lesão na córnea, pode-se afirmar que se trata de uma úlcera de córnea refratária. Sendo instituído o tratamento, pela remoção do epitélio corneano solto e administração de medicações tópicas e sistêmica.

Foi instilado uma gota do colírio de tropicamida (Tropicil ${ }^{\circledR}$ ) no olho acometido e 10 minutos após 2 gotas de colírio de oxibuprocaína (Anestocil ${ }^{\circledR}$ ). O desbridamento foi realizado com swab, aplicado na superfície da córnea de forma radial em direção ao limbo, até a remoção do epitélio não aderido. Foi prescrito uma gota de cloridrato de tobramicina $\left(\right.$ Tobrex $\left.^{\circledR}\right)$, uma gota de EDTA 0,35\% (manipulado), uma gota de soro autólogo (manipulado), uma gota do gel oftálmico de ganciclovir (Virgan ${ }^{\circledR}$ ) prescritas a cada 4 horas; uma gota de colírio de lubrificante $\left(\right.$ Liposic $\left.^{\circledR}\right)$ a cada 12 horas; uma gota de colírio de tropicamida (Tropicil Top ${ }^{\circledR}$ ) a cada 12 horas, durante 4 dias; uso do colar protetor do tipo elisabetano foi indicado, porém foi negado pelo proprietário.

Quinze dias após o desbridamento com swab, alcançou a redução em $70 \%$ da extensão da úlcera, contudo observou-se que a borda da lesão continuava irregular e elevada. $\mathrm{O}$ animal então, foi submetido a um segundo desbridamento com swab. Foi prescrito oxitetraciclina pomada $\left(\right.$ Ocil $\left.^{\circledR}\right)$, mantida a administração de uma gota de EDTA 0,35\%, uma gota de ganciclovir a cada 4 horas e uma gota de colírio de lubrificante a cada 12 horas.

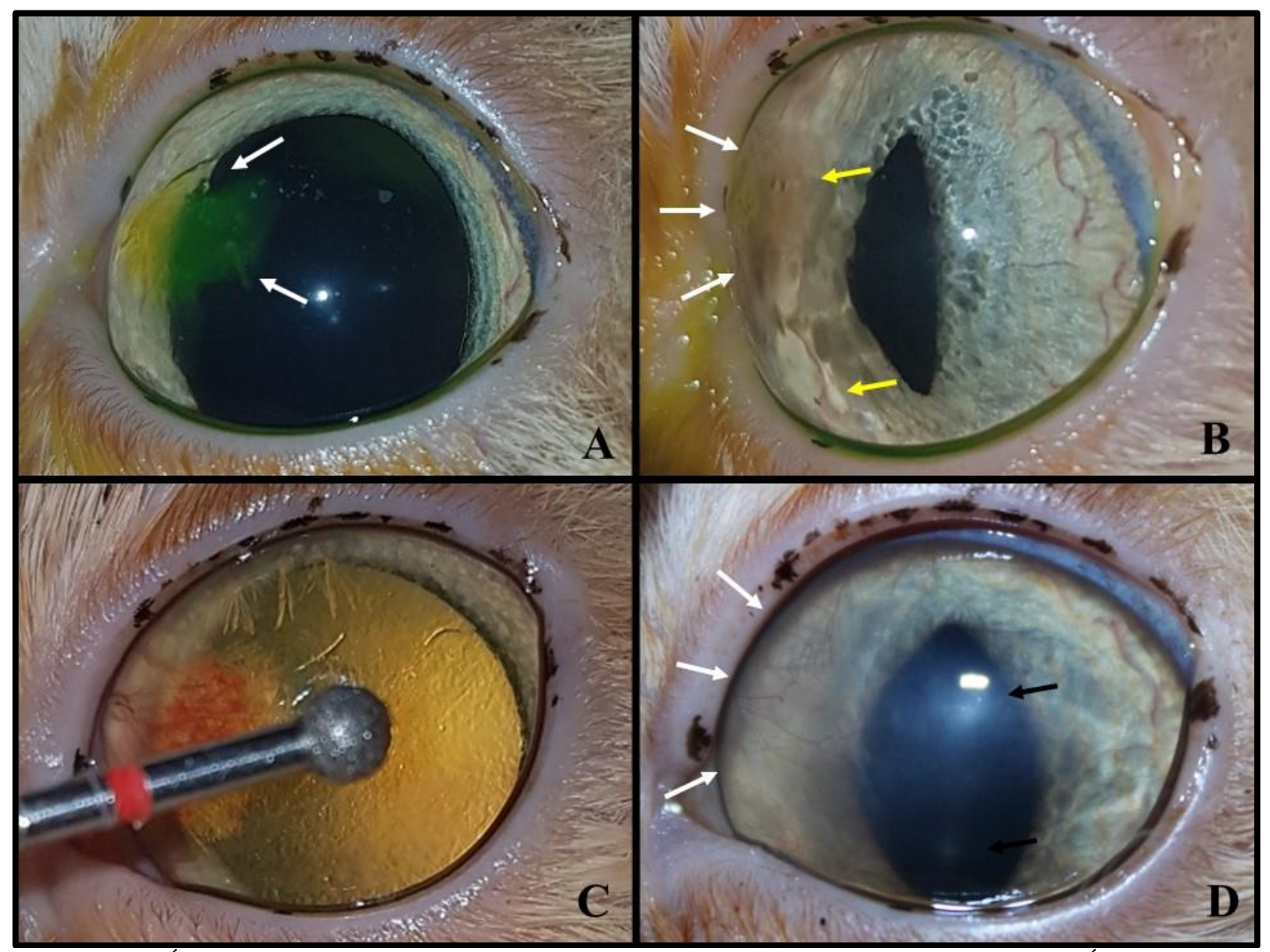

Figura1. (A) - Úlcera refratária com borda irregular e penetração da fluoresceína subeptelial (setas). (B) - Úlcera recidivante (setas brancas) com presença de discretas placas enegrecida na superfície da córnea (setas amarelas). (C) - Remoção total do epitélio não aderente e das placas enegrecidas com o emprego da DB. (D) - Resolução da úlcera refratária, observa-se tecido cicatricial, com intensificação da opacidade corneana nas regiões de exérese de tecido necrótico (setas pretas) e regressão na vascularização (setas brancas). 
Na reavaliação 17 dias após a segunda intervenção com swab, o animal não apresentava qualquer sinal de desconforto ocular. Foi observado vascularização na córnea sem presença de lesão. O teste de fluoresceína apresentou negativo, confirmando a integridade da córnea. Foi mantido ganciclovir a cada 4 horas e uma gota de colírio de lubrificante a cada 12 horas. $\mathrm{O}$ animal recebeu alta clínica e solicitado nova consulta em 30 dias.

Dezoito dias após a alta clínica, o animal foi consultado com queixa de recorrência de discreto blefarospasmo e epífora. Ao exame com a lâmpada em fenda, foi observado vascularização superficial e profunda da córnea, discretas placas necróticas, enegrecida na superfície coreana e úlcera com epitélio centro medial irregular. $O$ teste de fluoresceína apresentou-se positivo, penetrando o corante abaixo do epitélio não aderente (Figura 1B). Optou-se pelo desbridamento com emprego da DB (Diamond Burr, AlgerbrushII ${ }^{\circledR}$ ).

Para a ceratectomia superficial com a DB, o animal foi sedado com metadona $(0,3 \mathrm{mg} / \mathrm{kg}$, Semfortam $\left.{ }^{\circledR}\right)$ por via intramuscular e alfaxalona $\left(5 \mathrm{mg} / \mathrm{kg}\right.$, Alfaxan $\left.{ }^{\circledR}\right)$ administrado em bolus $(1 / 4 \mathrm{da}$ dose calculada) por via de acesso intravenoso, quando necessário durante o procedimento de ceratectomia superficial. Foi instilado uma gota do colírio de atropina (Atropocil ${ }^{\circledR}$ ) no olho acometido e cinco minutos após, uma gota de colírio oxibuprocaína. Previamente ao procedimento foi realizada a antissepsia da superfície da córnea e saco conjuntival com solução de iodo-povidona (PVPI) 5\%, sendo o excedente retirados pela aplicação de solução fisiológica estéril sobre a superfície ocular e saco conjuntival. Administrou-se novamente uma gota de colírio de oxibuprocaína sobre a superfície da córnea. A córnea foi previamente desbridada com swab e em ato contínuo ocorreu o desbridamento com a DB $(2,5 \mathrm{~mm})$, aplicada sobre a lesão e superfície corneana de forma delicada e em movimentos circulares, com remoção das áreas necróticas e remoção total de todo o epitélio não aderido (Figura 1C). A terapia pós ceratectomia com DB consistiu na administração de oxitetraciclina pomada, uma gota de EDTA 0,35\%, uma gota de soro autólogo e mantida a administração de uma gota do gel oftálmico de ganciclovir, prescritas a cada 4 horas; uma gota de colírio de lubrificante a cada 12 horas e $10 \mathrm{mg} / \mathrm{kg}$ de doxiciclina $\left(\operatorname{Ronaxan}^{\circledR}\right)$ foi administrado por via oral a cada 24 horas, durante 14 dias.

Quatorze dias após o desbridamento com DB, foi observado a presença de intensa vascularização e edema de córnea. Ao teste com fluoresceína revelou a presença de úlcera axial sem a presença de bordas livres. Foi prescrito ofloxacina $\left(\mathrm{Oflex}^{\circledR}\right)$ prescritas a cada 6 horas, mantida a administração de uma gota de EDTA $0,35 \%$, uma gota do gel oftálmico de Ganciclovir prescritas a cada 4 horas; uma gota de colírio de lubrificante a cada 12 horas. Foi mantida doxiciclina $(10 \mathrm{mg} / \mathrm{kg})$ por via oral a cada 24 horas, durante sete dias.

Quarenta e oito dias após o procedimento com a DB o animal não apresentava qualquer sinal de desconforto ocular, teste com fluoresceína não corou a superfície da córnea, estava presente vascularização corneana superficial, vasos fantasmas e evidente macula cicatricial em região axial. Onde encontrava-se as discretas zonas necrótica, foi observado além de tecido cicatricial a presença de discreta facetacorneana, evidenciada com lâmpada de fenda. Mantido uso ganciclovir a cada 4 horas, uma gota de colírio de lubrificante a cada 12 horas e indicado reavaliação em 30 dias.

Em setenta e oito dias após o desbridamento com DB, o animal apresentava-se confortável. O teste de fluoresceína manteve-se negativo, observou redução na vascularização corneana, vasos fantasmas estavam presentes, nébula e mácula demarcavam a área cicatrizada da úlcera refratária. Nas regiões de exérese de tecido necrótico foi observado intensificação da opacidade corneana, sem presença de faceta (Figura 1D). O uso de colírio lubrificante foi mantido em uso continuo a cada 12 horas e indicado reavaliações regulares.

\section{Discussão}

Dentre as nomenclaturas utilizadas para caracterizar úlceras de córnea superficial, sem causa aparente, sem comprometimento estromal e envolvendo um epitélio não aderente, podem ser nomeadas como úlcera refratária, úlcera do boxer (Maggs et al., 2017), defeitos epiteliais corneais crônicos espontâneos (Hung et al., 2020; Maggs et al., 2017), úlcera indolente (Crivellentin \& Borin-Crivelletin, 2015; Maggs et al., 2017) entre outros. A idade do felino atendido era de oito anos, tal como o relatado por Croix et al. (2001) em um estudo de 29 gatos com úlceras de córnea não cicatrizantes com uma idade média de sete anos e oito meses. 
A etiologia da falha na união entre células epiteliais e as camadas anteriores do estroma da córnea (Maggs et al., 2017) pode estar associadas à uma zona hialinizada acelular no estroma anterior (Dawson et al., 2017; Spertus et al., 2017), deficiência de hemidesmossomos, laminina, colágeno IV e VII (Crivellentin \& Borin-Crivelletin, 2015). Em gatos pode estar relacionada como um fator de predisposição em animais braquicefálicos (Croix et al., 2001; Laus, 2009) como a raça Persa e presença de infecção por FHV-1 (Maggs et al., 2017).

A úlcera refratária está descrita em humanos (Mamikonyan et al., 2018), elefante (Wolfer \& Rich, 1992), lhama (Jones et al., 2007), cães (Hung et al., 2020), equinos (Pigatto et al., 2017), aves (Gleeson et al., 2019; Waugh et al., 2017) e felinos (Maggs et al., 2017), como relatado neste caso.

O felino descrito, apresentava blefarospasmo, fotofobia e epífora, que são sinais clínicos observados em animais com úlcera refratária (Croix et al., 2001; Maggs et al., 2017). A observação de discreto edema de córnea com o contorno irregular e bordas elevadas, sem presença de sinais inflamatórios e ausência de vascularização, são achados clínicos que foram relatados por Laus \& Oriá (1999) em animais sem nenhuma história de trauma prévio e com úlcera refratária. Em infecções por FHV-1 pode ser observado conjuntivite unilateral ou bilateral com hiperemia, secreção ocular, quemose, blefarospasmo e úlceras de córnea geográficas ou dendríticas, que podem corar com rosa bengala (Maggs et al., 2017) ou verde lisamina (Crivellentin \& Borin-Crivelletin, 2015). Alterações conjuntivais e coloração da córnea para úlceras dendríticas com rosa bengala, estavam ausentes na avaliação clínica. O FHV-1 também pode desempenhar um papel na patogênese do sequestro de córnea (Maggs et al., 2017) como relatado em tratamento anterior do olho direito e observado a presença de discreta placa necrótica enegrecida após recorrência da lesão no olho esquerdo do animal descrito.

O diagnóstico foi realizado através da presença dos sinais clínicos aliados a presença de epitélio solto, que se desprendeu facilmente com a ponta de um swab estéril (Crivellentin \& Borin-Crivelletin, 2015). O teste com o corante de fluoresceína apresenta-se positivo e o corante pode penetrar no espaço subepitelial (Crivellentin \& Borin-Crivelletin, 2015). Possuem ainda curso prolongado e tendem a recidivar (Hvenegaard et al., 2011), corroborando com o curso clínico relatado. A pesquisa viral não foi autorizada pelo proprietário, sendo indicado a identificação de gatos infectados por FHV-1, pela pesquisa de material genético por técnica de PCR (Maggs et al., 2017). Na presença de sequestro de córnea a pesquisa por PCR no sangue e nas amostras corneais podem apresentar negativas na maior parte dos gatos que desenvolve a doença (Crivellentin \& Borin-Crivelletin, 2015). Alguns autores (Oriá et al., 2001; Stiles et al., 1997) sugeriram que o FHV-1 pode ser menos uma causa menos importante da doença em raças afetadas como Himalaia e Persa, do que outros fatores, como defeitos metabólicos da córnea e lagoftalmia.

O tratamento de escolha objetivou remover o epitélio frouxo, a fim de facilitar o crescimento de novas células epiteliais, com complexos de adesão mais fortes (Pigatto et al., 2017), associado ao tratamento terapêutico (Maggs et al., 2017). O tratamento terapêutico utilizado para a resolução da úlcera refratária, incluiu agentes antiprotease e antibióticos (Hvenegaard et al., 2011). Além, do uso de antiviral tópico, realizado mesmo com a etiologia viral não confirmada. Agentes antivirais tópicos podem ser utilizados por um período mínimo de duas semanas (Laus \& Oriá, 1999), podendo ser continuado para prevenir a recorrência em gatos com infecções por FHV-1 (Maggs et al., 2017).

O desbridamento pode ser realizado com swab estéril (Maggs et al., 2017), desbridamento químico (Hvenegaard et al., 2011), queratotomia em grade e punctata (estas não recomendadas em gatos) (Maggs et al., 2017) e por último a DB (Hung et al., 2020). Após recidivas da úlcera com emprego do swab, associados a presença de discretas placas necróticas enegrecida na superfície coreana, optou-se pelo procedimento de ceratectomia superficial com o emprego da DB, conforme realizado por Visser et al. (2019). Para o procedimento, o gato foi submetido a sedação e administração de colírio com anestésico, em ato continuo a córnea foi desbridada usando swab seguido de desbridamento com DB, tal como descrito no estudo realizado por Visser et al. (2019).

Após o desbridamento, foi observado intenso edema de córnea que reduziu conforme a epitelização. Devido à ausência do epitélio corneano hidrofóbico, ocorre a absorção passiva de água do filme lacrimal originando o edema de córnea, com a inflamação ocorre ainda o recrutamento de leucócitos, fribrobrastos e ativação vascular, apoiando a cicatrização da ferida na córnea (Maggs et al., 2017). A 
vascularização e fibrose da córnea que aumentam durante a cicatrização da úlcera, conforme relatado em cães por Edelmann et al. (2018). Após a cicatrização da córnea alguns vasos sanguíneos deixam de ser perfundidos, dando o aspecto de vasos fantasmas (Maggs et al., 2017). Como observado, a presença de vasos sanguíneos e processos inflamatórios da córnea, podem originar diferentes intensidades de opacificação (Maggs et al., 2017), sendo essas opacificações uma consequência indesejada na cicatrização coreana (Edelmann et al., 2018).

Devido a negação do uso do colar protetor pelo proprietário, a proteção mecânica da córnea com a terceira pálpebra, não foi realizada. O colar protetor deve ser utilizado para evitar auto-traumas (Maggs et al., 2017). Além disso o recobrimento da úlcera superficial com a membrana nictitante e lentes de contato terapêutica, podem acelerar a epitelização corneal (Crivellentin \& Borin-Crivelletin, 2015).

Quarenta e oito dias após o procedimento com a DB foi obtida a total epitelização corneal. Em gatos, o tempo médio entre desbridamento com DB e ausência de retenção de fluoresceína da córnea foi de 22,2 \pm 6 ,63dias num estudo de Visser et al. (2019), com 9 gatos. São raros os relatos de cicatrização de úlceras refratária em gatos tratados com $\mathrm{DB}$, documentados na literatura. Nesse caso, o desbridamento com a DB foi eficaz na resolução da úlcera refratária em um gato Persa, não ocorrendo complicações ou recorrência da úlcera, durante o período acompanhado.

\section{Conclusão}

A conformação braquicefálica deve ser considerada um fator etiológico em lesões ulcerativas refratárias e formação de sequestro de córnea em gatos. O emprego da DB, mostrou ser um dispositivo eficaz, de fácil aplicação, bem tolerado e seguro em sua execução, na resolução de úlcera de córnea refratária num gato da raça Persa.

\section{Agradecimentos}

Os autores agradecem a colaboração de toda a equipe do Hospital Veterinário Universitário de Coimbra (HVUC) e à Fundação de Ciência e Tecnologia (FCT), Portugal, (SFRH/BD/139319/2018).

\section{Referências bibliográficas}

Crivellentin, L. Z., \& Borin-Crivelletin, S. (2015). Casos de rotina em medicina veterinária de pequenos animais. In MedVet.

Croix, N. C. La, Woerdt, A. van der, \& Olivero, D. K. (2001). Nonhealing corneal ulcers in cats: 29 cases (1991-1999). Journal of the American Veterinary Medical Association, 218(5), 733-735. DOI: https://doi.org/10.2460/javma.2001.218.733

Dawson, C., Naranjo, C., Sanchez-Maldonado, B., Fricker, G. V, Linn-Pearl, R. N., Escanilla, N., Kafarnik, C., Gould, D. J., Sanchez, R. F., \& Matas-Riera, M. (2017). Immediate effects of diamond burr debridement in patients with spontaneous chronic corneal epithelial defects, light and electron microscopic evaluation. Veterinary Ophthalmology, 20(1), 11-15. DOI: https://doi.org/10.1111/vop.12337

Edelmann, M. L., Mohammed, H. O., Wakshlag, J. J., \& Ledbetter, E. C. (2018). Clinical trial of adjunctive autologous platelet-rich plasma treatment following diamond-burr debridement for spontaneous chronic corneal epithelial defects in dogs. Journal of the American Veterinary Medical Association, 253(8), 1012-1021. DOI: https://doi.org/10.2460/javma.253.8.1012

Gleeson, M. D., Moore, B. A., Edwards, S. G., Stevens, S., Childress, A. L., Wellehan Junior, J. F. X., Robertson, J., Murphy, C. J., Hawkins, M. G., \& Paul-Murphy, J. (2019). A novel herpesvirus associated with chronic superficial keratitis and proliferative conjunctivitis in a great horned owl (Bubo virginianus). Veterinary Ophthalmology, 22(1), 67-75. DOI: https://doi.org/10.1111/vop.12570

Grahn, B. H., \& Peiffer, R. L. (2007). Fundamentals of veterinary ophthalmic pathology. In K. N. Gelatt (Ed.), Veterinary ophthalmology (Vol. 1, pp. 355-437). Ames.

Hung, J. H., Leidreiter, K., White, J. S., \& Bernays, M. E. (2020). Clinical characteristics and treatment of spontaneous chronic corneal epithelial defects (SCCEDs) with diamond burr debridement. 
Veterinary Ophthalmology. DOI: https://doi.org/10.1111/vop.12772

Hvenegaard, A. P., Vieira, J. E., Leandro, D. C., Góes, A. C., Safatle, A., \& Barros, P. S. M. (2011). Retrospective study on clinical management of indolent ulcers in Boxer dogs. Pesquisa Veterinária Brasileira, 31(10), 910-915. DOI: https://doi.org/10.1590/s0100-736x2011001000012

Jones, M. L., Gilmour, M. A., \& Streeter, R. N. (2007). Use of grid keratotomy for the treatment of indolent corneal ulcer in a llama. The Canadian Veterinary Journal, 48(4), 416.

Laus, J. L. (2009). Oftalmologia clínica e cirúrgica em cães e gatos. Roca, Brasil.

Laus, José Luiz, \& Oriá, A. P. (1999). Doenças corneanas em pequenos animais. Revista de Educação Continuada Em Medicina Veterinária e Zootecnia Do CRMV-SP, 2(1), 23-33. DOI: https://doi.org/10.36440/recmvz.v2i1.3375

Maggs, D., Miller, P., \& Ofri, R. (2017). Slatter's Fundamentals of Veterinary Ophthalmology E-Book. Elsevier Health Sciences.

Malta, J. B. N. S., \& Soong, H. K. (2008). Diamond burr superficial keratectomy in the treatment of visually-significant anterior corneal lesions. Arquivos Brasileiros de Oftalmologia, 71(3), 415-418. DOI: https://doi.org/10.1590/s0004-27492008000300021

Mamikonyan, V. R., Trufanov, S. V, Tekeeva, L. Y., Malozhen, S. A., Subbot, A. M., \& Fyodorov, A. A. (2018). Polishing of Bowman's membrane with diamond burr in the treatment of recurrent corneal erosion syndrome. Vestnik Oftalmologii, 134(5. Vyp. 2), 162-167. DOI: https://doi.org/10.17116/oftalma2018134051162

McGrath, L. A., \& Lee, G. A. (2014). Techniques, indications and complications of corneal debridement. Survey of Ophthalmology, 59(1), 47-63. DOI: https://doi.org/10.1016/j.survophthal.2013.03.004

Oriá, A. P., Soares, A. M. B., Laus, J. L., \& Neto, F. (2001). Seqüestração corneana dos felinos. Ciência Rural, 31(31), 553-556. https://doi.org/10.1590/s0103-84782001000300032

Pigatto, J. A. T., Albuquerque, L., Oliveira Bacchin, Â. B. O., Silva, G. M. R., Petersen, M. B., \& Reiter, G. G. (2017). Diamond burr for the treatment of an indolent corneal ulcer in a foal. Acta Scientiae Veterinariae, 45, 4.

Silva, E. G., Powell, C. C., Gionfriddo, J. R., Ehrhart, E. J., \& Hill, A. E. (2011). Histologic evaluation of the immediate effects of diamond burr debridement in experimental superficial corneal wounds in dogs. Veterinary Ophthalmology, 14(5), 285-291. DOI: https://doi.org/10.1111/j.14635224.2010.00869.x

Spertus, C. B., Brown, J. M., \& Giuliano, E. A. (2017). Diamond burr debridement vs. grid keratotomy in canine SCCED with scanning electron microscopy diamond burr tip analysis. Veterinary Ophthalmology, 20(6), 505-513. DOI: https://doi.org/10.1111/vop.12460

Stiles, J., McDermott, M., Bigsby, D., Willis, M., Martin, C., Roberts, W., \& Greene, C. (1997). Use of nested polymerase chain reaction to identify feline herpesvirus in ocular tissue from clinically normal cats and cats with corneal sequestra or conjunctivitis. American Journal of Veterinary Research, 58(4), 338-342.

Visser, H. E., Millichamp, N. J., Budelsky, C.L., Steele, K. A., Dees, D. D. (2019). Results of diamond burr debridement in cats: 9 cases. In: abstracts: The 49th annual scientific meeting of the American College of Veterinary Ophthalmologists, Minneapolis, Minnesota, Sept 26-29, 2018. Veterinary Ophthalmology.

Waugh, L., Pucket, J., Cole, G. A., \& D’Agostino, J. (2017). Management of a nonhealing, superficial corneal ulcer in a hyacinth macaw (anodorhynchus hyacinthinus). Journal of Avian Medicine and Surgery, 31(3), 239-243. DOI: https://doi.org/10.1647/2016-183

Wolfer, J., \& Rich, P. (1992). Persistent corneal erosion in an Asian elephant. The Canadian Veterinary Journal, 33(5), 337.

Recebido: 26 de maio, 2020.

Aprovado: 27 de junho, 2020

Disponível online: 31 julho, 2020.
Licenciamento: Este artigo é publicado na modalidade Acesso Aberto sob a licença Creative Commons Atribuição 4.0 (CC-BY 4.0), a qual permite uso irrestrito, distribuição, reprodução em qualquer meio, desde que o autor e a fonte sejam devidamente creditados. 